\title{
Prevalence of Obesity and Metabolic Syndrome in Adult Population of Selected Regions of the Czech Republic. Relation to Eating Habits and Smoking
}

\author{
Vosátková M.1, Čeřovská J.², Zamrazilová H.², Hoskovcová P. ${ }^{1}$, \\ Dvořáková M. ${ }^{3}$, Zamrazil V. ${ }^{3}$ \\ ${ }^{1}$ Department of Biochemistry, Institute of Endocrinology, Prague, Czech Republic; \\ 2Obesity Management Center, Institute of Endocrinology, Prague, Czech Republic; \\ ${ }^{3}$ Department of Clinical Endocrinology, Institute of Endocrinology, Prague, Czech \\ Republic
}

Received November 11, 2011; Accepted June 25, 2012.

Key words: Obesity - Metabolic syndrome - Eating inventory - Smoking - Sleeping

Abstract: Prevalence of the metabolic syndrome is around 25\% in Europe but its occurrence grows in both genders with increasing age and weight. Lifestyle factors may contribute to the risk of developing metabolic syndrome. The objective of this study was to determine the relationship between metabolic syndrome and eating habits as well as length of sleep and smoking. Participants (519 women and 286 men aged 18-65 years) were chosen by random selection and questioned about their eating habits, sleep length and smoking. This information was combined with anthropometric and clinical parameters of metabolic syndrome. The female group was divided into two subgroups depending on climacteric stage (before and after menopause). Metabolic syndrome prevalence does not differ between regions in neither female (29.9\%) nor male (32.5\%) group. Body mass index $\geq 25$ was detected in $50.4 \%$ of all women and $65.7 \%$ of men; $23.5 \%$ of all women and $21.7 \%$ men had body mass index $\geq 30$. In conclusion, metabolic syndrome prevalence was proved to depend on eating habits and family heredity. Positive correlation between the above mentioned factors demonstrated itself in the total sample but not in individual regions. Metabolic syndrome prevalence in Czech adults is comparable with neighbouring countries. No significant interregional differences in metabolic syndrome prevalence within the Czech Republic were detected. In conclusion, relationship between eating habits and metabolic syndrome was confirmed.

This study was supported by grant No. NR 7763-3 of the IGA MZCR.

Mailing Address: Mgr. Michala Vosátková, Department of Biochemistry, Institute of Endocrinology, Národní 8, 11694 Prague 1, Czech Republic; Phone: +420 224905 325; Fax: +420 224905 325; e-mail: mvosatkova@endo.cz 


\section{Introduction}

The International Diabetes Federation (IDF) released a world-wide recommended consensual statement in 2005 that contains a new definition of metabolic syndrome. It is characterized by the presence of abdominal obesity, a higher concentration of triacylglycerols, decreased high density lipoprotein cholesterol concentration, hypertension and hyperglycaemia after fasting. Unlike in other classifications, central obesity in the IDF statement is considered a basic characteristic of metabolic syndrome (Pouliot et al., 1994; Anderson et al., 2001; IDF, 2005). The study results have confirmed that the metabolic syndrome is a major predictor of mortality and morbidity due to cardiovascular causes (Galassi et al., 2006; Gami et al., 2007). It is estimated that 20-30\% European population is affected by this syndrome (Cameron et al., 2004; Qiao, 2006; Hildrum et al., 2007). Czech epidemiological study MONICA revealed that metabolic syndrome occurs in $24.4 \%$ of women and $32.0 \%$ of men aged $25-64$ years (Pelikanova, 2003). Nowadays, obesity is becoming a very serious problem affecting the whole society. Obesity prevalence increasing steadily, the condition is reaching pandemic levels.

A study by Kunesova et al. (2006), which focused on the occurrence of overweight and obesity in the Czech Republic, reveals overweight (body mass index $>25.0$ ) in $52 \%$ and obesity (body mass index $>30.0$ ) in $17 \%$ of adults in both gender groups. Biochemical, somatic, endocrine and genetic differences between the obese and healthy population rank obesity among pathologies that require a complex methodological approach and individual therapy. Obesity is defined by a distinct body composition with significantly increased amount of adipose tissue. Metabolic risk factors can be identified already in childhood (Baker et al., 2007; BibbinsDomingo et al., 2007; Ho, 2009;Virdis et al., 2009). Changes in lipid and glucose metabolism are present in biochemical profiles of obese and overweight patients. These changes are expressed by a tendency to develop premature atherosclerosis, glucose intolerance manifestations, hyperinsulinemy and insulin resistance.

The latter can lead to the development of Diabetes Mellitus type II (Sorof and Daniels, 2002; Glen et al., 2004; Weiss et al., 2004). Socioeconomic impact of obesity cannot be ignored either. E.g. in the USA, 5-7\% of total health care expenditures (i.e. more than 100 billion dollars) are spent on treating obesity complications (Finkelstein et al., 2005; Ludwig and Pollack, 2009).

The aim of the study was to detect the obesity and metabolic syndrome prevalence and examine connections between metabolic syndrome and eating habits and other factors, such as smoking and the length of sleep.

\section{Methods}

Between 2004 and 2006, health status of the population, with special focus on thyroid gland diseases, was monitored in three regions across the Czech Republic, including Jablonec nad Nisou (North Bohemia), Pribram (Central Bohemia) and Zdar nad Sazavou (East Bohemia); (Zamrazil et al., 2004). Metabolic 
syndrome prevalence was also monitored, so was its relation to eating habits and smoking.

Questionnaires about personal and family history, eating habits and life style were sent to the participants in advance and were filled out with them as part of the examination session.

The answers are therefore equally valuable as information obtained in controlled interviews. All examinations were held each year between the second half of April and the first half of June. The age structure of both men and women in the sample was homogenous in all regions. Women were divided into two subgroups according to their climacteric stage - before menopause (women in reproduction age, premenopause, perimenopausal) and after menopause (women more than a year after the last menstrual cycle). The study was approved by the Ethics Committee of the Institute of Endocrinology and conducted in accordance with the Helsinki Declaration. All participants received oral and written information about the project and signed informed consent.

\section{Anthropometric and clinical examinations}

Body height, waist and hip circumference were measured with $0.1 \mathrm{~cm}$ precision, and body weight with $0.1 \mathrm{~kg}$ precision. Body mass index and waist to hip ratio were calculated.

Blood pressure was taken with a mercury tonometer, while sitting, after 30 minutes of rest.

\section{Biochemical examinations}

Blood samples were taken in the morning after a night-long fasting. Biochemical parameters (high-density lipoprotein cholesterol, triacylglycerols, glycemia) were determined spectrophotometrically using the Cobas Integra 400 Plus analyzer (Roche Diagnostics). C-peptide and insulin were determined by the imunoelectrochemiluminiscence method using the Modular E170 analyzer (Roche Diagnostics).

\section{Metabolic syndrome definition}

Metabolic syndrome was determined based on criteria recommended by the International Diabetes Federation 3 - central obesity (waist circumference $\geq 94 \mathrm{~cm}$ in men, $\geq 80 \mathrm{~cm}$ in women) plus at least two from the following parameters: triacylglycerols $\geq 1.7 \mathrm{mmol} / \mathrm{l}$; high-density lipoproteins cholesterol $<1.03 \mathrm{mmol} / \mathrm{l}$ in men or $<1.29 \mathrm{mmol} / \mathrm{l}$ in women; systolic blood pressure $\geq 130 \mathrm{~mm} \mathrm{Hg}$ or diastolic blood pressure $\geq 85 \mathrm{~mm} \mathrm{Hg}$; glycemia level $\geq 5.6 \mathrm{mmol} / \mathrm{l}$.

\section{Questionnaires}

The questionnaires were designed to gain information about consumption quantity, consumption frequency and food type preference. 
Respondents answered the following questions:

Which daily meal is the largest? Offered answers: breakfast, morning snack, lunch, afternoon snack, supper.

How many meals a day do you usually have?

What time do you usually have breakfast and supper?

Which dairy products do you prefer? Offered answers: light; low-fat or skimmed milk; fat i.e. the respondent prefers cream yogurt, fat cheese, milk.

What kind of meat do you prefer? Offered answers: lean - e.g. chicken; fat - e.g. pork, bacon.

Which processed meat products do you prefer? Offered answers: lean - ham, processed chicken products; fat - sausage, salami.

What kind of fat do you eat with pastry, bread? Offered answers: butter; margarine or vegetable fat; margarine light; no fat at all.

How often do you eat processed meat, meat, fish, legumes? Offered answers: not at all; less than $1 \times$ per week; $1 \times$ per week; $2-6 \times$ per week; every day.

Questionnaires referring to personal, family history, lifestyle and smoking included these questions:

Obesity in family - in mother, father.

Changes in body weight during the past 10 years.

Average daily length of sleep.

Smoking. Smoker - includes categories regular smoker, i.e. at the time of the study smokes at least 1 cigarette a day, and occasional smoker, i.e. at the time of the study smokes less than 1 cigarette a day. Non-smoker - includes categories former smoker, i.e. smoked during lifetime more than 100 cigarettes and doesn't smoke anymore, and non-smoker, i.e. ever smoked less than 100 cigarettes in total (Chollat-Traquet, 1996).

\section{Statistic processing}

Statgraphics Plus program, version 7.1, was used, along with the categorical data analysis with chi-square statistics and the ANOVA variance analysis. Normality test was applied to quantitative parameters; wherever values appeared in a nonGaussian distribution, logarithmic transformation or alternatively the Kruskal-Wallis test was used. Spearman and partial correlation analysis were used for affinity testing of tested variables to uncover hidden relations and detect false relations, respectively.

\section{Results}

Basic anthropometric, biochemical and clinical characteristics of the monitored group are shown in Table 1. No significant differences in metabolic syndrome prevalence were found between the groups (women before menopause; women after menopause; men) and between different regions including Jablonec nad Nisou, 





Pribram and Zdar nad Sazavou. For this reason, data from the three locations were evaluated together in subsequent analysis. Correlation between metabolic syndrome occurrence and group type (women before menopause; women after menopause; men) was confirmed. The total metabolic syndrome prevalence in men and women was $26.4 \%$ (women $22.9 \%$, men $32.5 \%$ ). Body mass index $\geq 25$ was found in $50.4 \%$ of all women and $65.7 \%$ of men. Body mass index $\geq 30$ was found in $23.5 \%$ of all women and $21.7 \%$ of men. The largest weight gains (disregarding their presence or absence metabolic syndrome) during the past ten years were reported by women after menopause (women after menopause $6.22 \pm 7.81 \mathrm{~kg}$ vs. women before menopause $3.94 \pm 8.50 \mathrm{~kg}$, men $4.33 \pm 8.72 \mathrm{~kg}$ ).

Table 2 shows how many individuals in the monitored groups metabolic syndrome criteria in various parameters (waist circumference, blood pressure, high-density lipoprotein cholesterol, triacylglycerols, glycemia). Critical values in individual parameters were reached especially by women after menopause (e.g. critical value of waist circumference was exceeded in $85 \%$ of women, of systolic blood pressure in $57 \%$ of women, diastolic blood pressure in $49 \%$ of women).

The average number of meals a day was in all women $4.14 \pm 1.02$, in all men $3.83 \pm 1.04$. Most respondents stated that lunch was their largest meal - in total 226 men (79\%) and 395 women (76\%).

Table 2 - Prevalence of individual metabolic abnormalities of metabolic syndrome

\begin{tabular}{lccccccc}
\hline & $\begin{array}{c}\mathrm{N} \\
(\%)\end{array}$ & $\begin{array}{c}\text { Waist } \\
\text { circumference } \\
(\mathrm{cm})\end{array}$ & $\begin{array}{c}\text { SBP } \\
(\mathrm{mm} \mathrm{Hg})\end{array}$ & $\begin{array}{c}\text { DBP } \\
(\mathrm{mm} \mathrm{Hg})\end{array}$ & $\begin{array}{c}\text { TAG } \\
(\mathrm{mmol} / \mathrm{l})\end{array}$ & $\begin{array}{c}\text { HDL-C } \\
(\mathrm{mmol} / \mathrm{l})\end{array}$ & $\begin{array}{c}\text { Glycemia } \\
(\mathrm{mmol} / \mathrm{l})\end{array}$ \\
\hline Premenopausal & 340 & 198 & 63 & 68 & 44 & 10 & 20 \\
women & $(100 \%)$ & $(58.2 \%)$ & $(18.5 \%)$ & $(20 \%)$ & $(11.8 \%)$ & $(2.9 \%)$ & $(5.9 \%)$ \\
\hline Postmenopausal & 179 & 153 & 102 & 88 & 53 & 36 & 48 \\
women & $(100 \%)$ & $(85.5 \%)$ & $(57.0 \%)$ & $(49.2 \%)$ & $(29.6 \%)$ & $(20.1 \%)$ & $(26.8 \%)$ \\
\hline Men & 286 & 183 & 128 & 128 & 86 & 58 & 72 \\
& $(100 \%)$ & $(64.0 \%)$ & $(44.8 \%)$ & $(44.8 \%)$ & $(30.1 \%)$ & $(20.3 \%)$ & $(25.2 \%)$ \\
\hline
\end{tabular}

DBP - diastolic blood pressure; HDL-C - high-density lipoprotein cholesterol; SBP - systolic blood pressure; TAG - triacylglycerols

The average number of smokers was $19.4 \%$ of all women and $24.5 \%$ of all men under examination. Metabolic syndrome prevalence was significantly higher $(p=0.03)$ in the subgroup of women before menopause who are smokers than in the subgroup of women before menopause who are non-smokers. Metabolic syndrome prevalence did not differ between smokers and non-smokers in the subgroup of women after menopause and the group of men. Waist circumference and body mass index of smoking and non-smoking individuals did not differ to a statistically significant degree. 
The average length of sleep in the group of all women is $7.22 \pm 1.10$ hours, in the group of men $7.19 \pm 1.12$ hours. Gender, metabolic syndrome occurrence or menopause have no effect on the average length of sleep.

Correlations between metabolic syndrome occurrence (present, absent), group type (women before menopause; women after menopause; men) and monitored parameters (eating behaviour, smoking, sleep length, obesity in family) are presented in Table 3. Significant correlations were found between metabolic syndrome diagnosis, group type and the following observed parameters: consumption of margarine, butter, fatty dairy products, low-fat dairy products, number of meals per day, change in body weight during the past ten years.

\section{Table 3 - Interaction between factor A (metabolic syndrome) or A + B (group - premenopausal women; postmenopausal women; men) with factor $\mathbf{C}$ (the consumption of selected food groups, number of meals per day and weight change over the last 10 years)}

\begin{tabular}{cccc}
\hline Factor A or A and B & Factor C & Partial chi-square test & P-value \\
\hline A + B & margarine & 7.65 & 0.022 \\
A & FDP & 5.59 & 0.018 \\
A & LFDP & 3.97 & 0.046 \\
A & butter & 5.33 & 0.021 \\
A & BMI & 151.70 & 0.000 \\
A & number of foods per day & 5.41 & 0.020 \\
A & weight change (kg) & 30.43 & 0.000 \\
\hline No interaction & sleep, smoking/no-smoking, number of cigarettes per day, frequency \\
& \multicolumn{2}{c}{ of intake legumes, bread, sausage } \\
\hline
\end{tabular}

Factor A - metabolic syndrome; factor B - group (premenopausal women, postmenopausal women and men); factor $\mathrm{C}$ - some of the monitored parameters; weight change $(\mathrm{kg})$ - weight change over the last 10 years; $\mathrm{BMI}$ - body mass index; FDP - fat dairy products; LFDP - low-fat dairy products

However, subsequent statistical analysis of these significant correlations did not confirm any notable differences between groups (women before menopause; women after menopause; men). No relevant correlations were proved between metabolic syndrome occurrence and parameters such as sleep length or smoking (Table 4).

\section{Discussion}

Our results of metabolic syndrome prevalence (total $26.4 \%$, women $22.9 \%$, men $32.5 \%$ ) are in accordance with earlier published data on European populations (Cameron et al., 2004; Galassi et al., 2006; Hildrum et al., 2007). Previous 


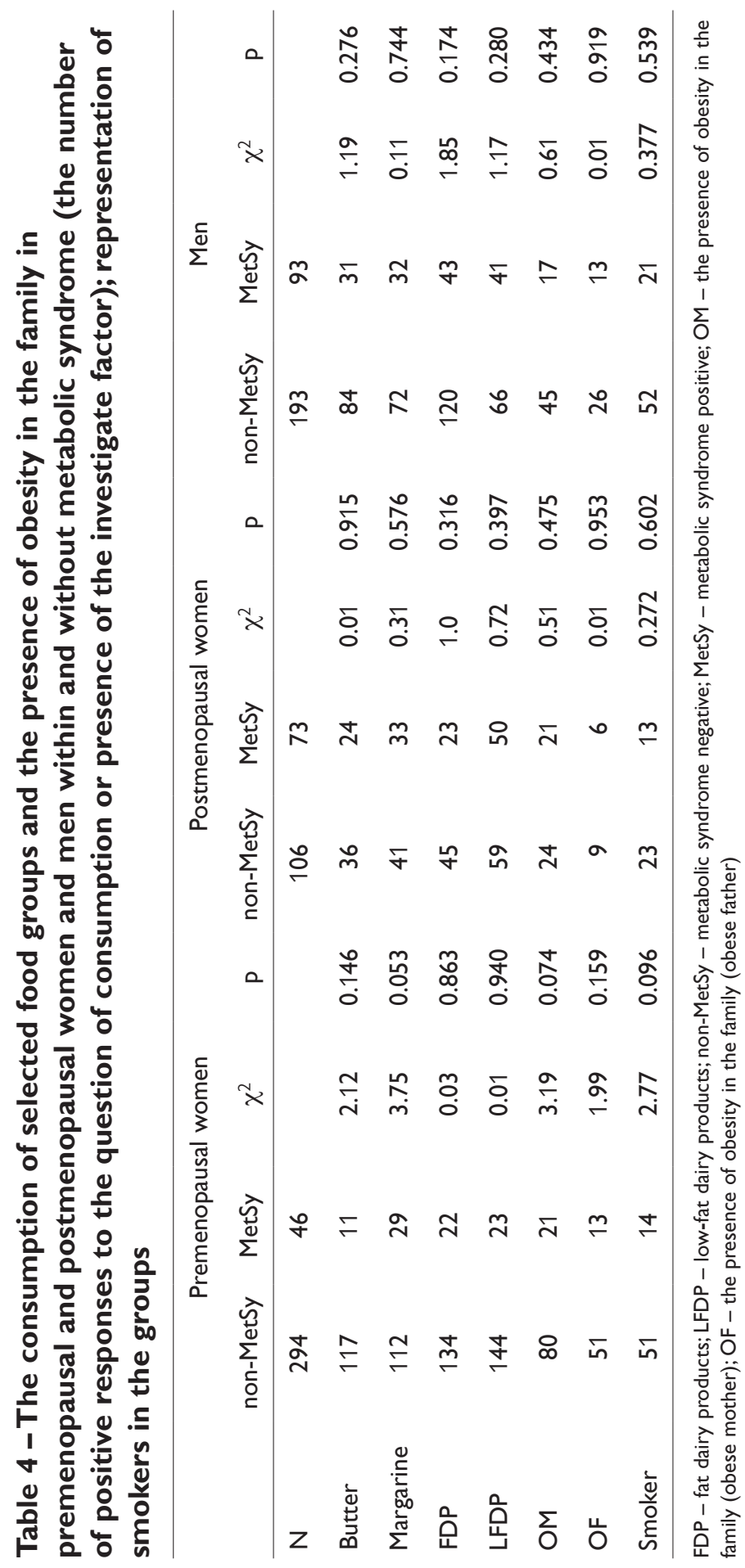

Metabolic Syndrome and Eating Habits 
epidemiological investigations carried out as a part of the MONIKA study among the Czech population discovered $32 \%$ and $24 \%$ occurrence in adult men and women, respectively, below 65 years of age (Cifkova and Skodova, 2004; Cifkova et al., 2004). The results of a wide-spread epidemiological study carried out among the US population show metabolic syndrome prevalence of $23.9 \%$ as defined by the criteria of the National Cholesterol Education Program Adult Treatment Panel III and $25.1 \%$ according to World Health Organization criteria (Ford and Giles, 2003). No differences in metabolic syndrome or obesity prevalence were found among the three monitored regions of the Czech Republic. The number of inhabitants of each of these regions was around 23,000-45,000 in 2008. Geographic characteristics of the regions were in no relation to obesity or metabolic syndrome prevalence. Similarity in life style and daily routine of respondents living in medium-size cities affects the monitored parameters to a greater degree. Metabolic syndrome prevalence in our monitored groups of women and men was related to eating habits. We found interesting correlations between the occurrence of metabolic syndrome and e.g. consumption of butter, margarine, dairy products or the number of meals per day (Table 3). Positive effects of dairy products consumption on blood pressure are mentioned in previous studies (Azadbakht et al., 2005; Steffen et al., 2005). A significant relation between some metabolic syndrome parameters (blood pressure, glycemia) and dairy product consumption was discovered e.g. in Hoorn study. Similar to our study, however, it did not reveal any significant effect of dairy product intake on body weight (Snijder et al., 2007). Relation between the consumption of red or white meat and metabolic syndrome prevalence, or any other of the followed parameters, was proved. Nonetheless the Kontogianni et al. (2008) study proved a notably higher risk of an acute coronary syndrome in individuals eating red meat frequently (more than 8 servings per month) compared to individuals with low consumption (less than 4 servings per month).

Relations between smoking and insulin resistance (Facchini et al., 1992; Targher et al., 1997), ischemic heart disease (Luksiene et al., 2008), body weight and weight change, and other cardiometabolic risks (Chiolero et al., 2008) are described in many earlier studies. A study carried out among more than five thousand Japanese clearly proved a lower prevalence of all metabolic syndrome parameters in nonsmokers compared with smokers (Ishizaka et al., 2005). Our study, however, failed to confirm these findings, most likely because of the relatively small sample size.

In our study we also focused on possible relations between metabolic syndrome and sleep length. Negative effects of excessive or insufficient length of sleep on metabolic syndrome prevalence are described in earlier studies (Choi et al., 2008; Hall et al., 2008). Chronic sleep deficiency is indicated as a possible risk factor for insulin resistance, Diabetes Mellitus type II and weight gain in an article by Spiegel et al. (2005). In our study, relations between sleep length and metabolic syndrome were not confirmed in any of the monitored groups. 


\section{Conclusion}

Prevalence of metabolic syndrome is increasing steadily across various populations. Its occurrence in younger age group is especially alarming. Occurrence of metabolic syndrome carries serious risks, such as cardiovascular and cerebrovascular morbidity. Despite a genetic background of the disorder, its emergence and development are strongly influenced by life style. Therefore, treatment of metabolic syndrome manifestations is insufficient without addressing its root causes.

\section{References}

Anderson, P. J., Critchley, J.A., Chan, J. C., Cockram, C. S., Lee, Z. S., Thomas, G. N. (2001) Factor analysis of the metabolic syndrome: obesity vs. insulin resistance as the central abnormality. Int. J. Obes. Relat. Metab. Disord. 25, 1782-1788.

Azadbakht, L., Mirmiran, P., Esmaillzadeh, A., Azizi, F. (2005) Dairy consumption is inversely associated with the prevalence of the metabolic syndrome in Tehranian adults. Am. J. Clin. Nutr. 82, 523-530.

Baker, J. L., Olsen, L.W., Sørensen, T. I. (2007) Childhood body-mass index and the risk of coronary heart disease in adulthood. N. Engl. J. Med. 357, 2329-2337.

Bibbins-Domingo, K., Coxson, P., Pletcher, M. J., Lightwood, J., Goldman, L. (2007) Adolescent overweight and future adult coronary heart disease. N. Engl. J. Med. 357, 2371-2379.

Cameron, A. J., Shaw, J. E., Zimmet, P. Z. (2004) The metabolic syndrome: prevalence in worldwide populations. Endocrinol. Metab. Clin. North Am. 33, 351-375.

Chiolero, A., Faeh, D., Paccaud, F., Cornuz, J. (2008) Consequences of smoking for body weight, body fat distribution, and insulin resistance. Am. J. Clin. Nutr. 87, 801-809.

Choi, K. M., Lee, J. S., Park, H. S., Baik, S. H., Choi, D. S., Kim, S. M. (2008) Relationship between sleep duration and the metabolic syndrome: Korean National Health and Nutrition Survey 2001. Int. J. Obes. (Lond.) 32, 1091-1097.

Chollat-Traquet, C. (1996) Evaluating Tobacco Control Activities: Experience and Guiding Principles. World Health Organisation, Geneva.

Cifkova, R., Skodova, Z. (2004) Longitudinal trends in major cardiovascular disease risk factors in the Czech population. Cas. Lek. Cesk. 143, 219-226. (in Czech)

Cifkova, R., Skodova, Z., Lanska, V., Adamkova, V., Novozamska, E., Jozifova, M. (2004) Prevalence, awareness, treatment and control of hypertension in the Czech Republic. Results of two nationwide cross-sectional surveys in 1997/1998 and 2000/2001. Czech Post-MONICA Study. J. Hypertens. 2(18), 571-579.

Facchini, F. S., Hollenbeck, C. B., Jeppesen, J., Chen, Y. D., Reaven, G. M. (1992) Insulin resistance and cigarette smoking. Lancet 339, 1128-1130.

Finkelstein, E. A., Rum, C. J., Kosa, K. M. (2005) Economic causes and consequences of obesity. Annu. Rev. Public Health 26, 239-257.

Ford, E. S., Giles, W. H. (2003) A comparison of the prevalence of the metabolic syndrome using two proposed definitions. Diabetes Care 26, 575-581.

Galassi, A., Reynolds, K., He, J. (2006) Metabolic syndrome and risk of cardiovascular disease: a meta-analysis. Am. J. Med. 119, 812-819.

Gami, A. S., Witt, B. J., Howard, D. E., Erwin, P. J., Gami, L. A., Somers, V. K., Montori, V. M. (2007) Metabolic syndrome and risk of incident cardiovascular events and death: a systematic review and meta-analysis of longitudinal studies. J. Am. Coll. Cardiol. 49, 403-414.

Glen, E. D., Sierra, M. L., Xiao-Hua, Z. (2004) Prevalence and trends of a metabolic syndrome phenotype among U.S. adolescents, 1999-2000. Diabetes Care 27, 2438-2443. 
Hall, M. H., Muldoon, M. F., Jennings, J. R., Buysse, D. J., Flory, J. D., Manuck, S. B. (2008) Self-reported sleep duration is associated with the metabolic syndrome in midlife adults. Sleep 31, 635-643.

Hildrum, B., Mykletun, A., Hole, T., Midthjell, K., Dahl, A. A. (2007) Age-specific prevalence of the metabolic syndrome defined by the International Diabetes Federation and the National Cholesterol Education Program: the Norwegian HUNT 2 study. BMC Public Health 7, 220.

Ho, T. F. (2009) Cardiovascular risks associated with obesity in children and adolescents. Ann. Acad. Med. Singapore 38, 48-49.

International Diabetes Federation (IDF) (online). 2005 (cit. 2010-12-31). IDF Worldwide Definition of the Metabolic Syndrome. Available at: www.idf.org

Ishizaka, N., Ishizaka, Y., Toda, E., Hashimoto, H., Nagai, R., Yamakado, M. (2005) Association between cigarette smoking, metabolic syndrome, and carotid arteriosclerosis in Japanese individuals. Atherosclerosis 181, 381-388.

Kontogianni, M. D., Panagiotakos, D. B., Pitsavos, C., Chrysohoou, C., Stefanadis, C. (2008) Relationship between meat intake and the development of acute coronary syndromes: the CARDIO2000 case-control study. Eur. J. Clin. Nutr. 62, 171-177.

Kunesova, M., Cechova, M., Laika, M. (2006) Project report: Lifestyle and obesity. Quantitative research on STEM/MARK for Ministry of Health and Czech Society for the Study of Obesity. (in Czech). www.obesitas.cz/download/dospeli_web.ppt

Ludwig, D. S., Pollack, H.A. (2009) Obesity and the economy: from crisis to opportunity. JAMA 301, 533-535.

Luksiene, D. I., Cerniauskiene, L. R., Margeviciene, L., Tamosiūnas, A. (2008) Changes in the prevalence of metabolic syndrome and smoking habits during a 10-year period and relation between these risk factors and ischemic heart disease among men aged 45-64 years. Medicina (Kaunas) 44, 400-406. (in Lithuanian)

Pelikanova, T. (2003) The metabolic syndrome. Vnitr. Lek. 49, 900-906. (in Czech)

Pouliot, M. C., Després, J. P., Lemieux, S., Moorjani, S., Bouchace, C., Tremblay, A. (1994) Waist circumference and abdominal sagittal diameter: Best simple anthropometric indexes of abdominal visceral adipose tissue accumulation and related cardiovascular risk in men and women. Am. J. Cardiol. 73, 460-468.

Qiao, Q. (2006) Comparison of different definitions of the metabolic syndrome in relation to cardiovascular mortality in European men and women. Diabetologia 49, 2837-2846.

Snijder, M. B., Van der Heijden, A. A., Van Dam, R. M., Stehouwer, C. D., Hiddink, G. J., Nijpels, G. (2007) Is higher dairy consumption associated with lower body weight and fewer metabolic disturbances? The Hoorn Study. Am. J. Clin. Nutr. 85, 989-995.

Sorof, J., Daniels, S. (2002) Obesity hypertension in children. J. Hypertens. 40, 441-447.

Spiegel, K., Knutson, K., Leproult, R., Tasali, E., Van Kauter, E. (2005) Sleep loss: a novel risk factor for insulin resistance and Type 2 diabetes. J. Appl. Physiol. 99, 2008-2019.

Steffen, L. M., Kroenke, C. H., Yu, X., Pereira, M. A., Slattery, M. L., Van Horn, L., Gross, M. D., Jacobs, D. R. Jr. (2005) Associations of plant food, dairy product, and meat intakes with 15-y incidence of elevated blood pressure in young black and white adults: the Coronary Artery Risk Development in Young Adults (CARDIA) Study. Am. J. Clin. Nutr. 82, 1169-1177.

Targher, G., Alberiche, M., Zenere, M. B., Bonadonna, R. C., Muggeo, M., Bonora, E. (1997) Cigarette smoking and insulin resistance in patients with noninsulin-dependent diabetes mellitus. J. Clin. Endocrinol. Metab. 82, 3619-3624.

Virdis, A., Ghiadoni, L., Masi, S., Versari, D., Daghini, E., Giannarelli, C. (2009) Obesity in the childhood: a link to adult hypertension. Curr. Pharm. Des. 15, 1063-1071.

Weiss, R., Dziura, J., Burgert, T. S., Tamborlane,W.V., Takali, S. E., Yeckel, C.W. (2004) Obesity and metabolic syndrome in children and adolescents. N. Engl. J. Med. 350, 2362-2374.

Zamrazil, V., Bilek, R., Cerovska, J., Delange, F. (2004) The elimination of iodine deficiency in the Czech Republic: the steps toward success. Thyroid 14(1), 49-56. 